\title{
Finite element analysis of heat flow through longitudinal finned tubes in the LNG ambient air vaporizer for a total frost case
}

\author{
Filip Lisowski ${ }^{{ }^{*}}$ and Edward Lisowski ${ }^{2}$ \\ ${ }^{1}$ Cracow University of Technology, Department of Machine Design and Composite Structures, Cracow, Poland \\ ${ }^{2}$ Cracow University of Technology, Department Applied Informatics, Cracow, Poland
}

\begin{abstract}
Liquefied natural gas (LNG) is transported and stored in liquid state at temperature of $-163^{\circ} \mathrm{C}$. In order to use natural gas directly in its gaseous form, LNG must be vaporized, which requires the input of heat. Ambient air vaporizers (AAVs) are commonly used for that purpose in LNG regasification stations. These heat exchangers consist of longitudinally finned tubes with a large heat transfer surface area, provide high efficiency and are virtually cost-free since the heat is taken from the ambient air. This paper presents the results finite element thermal analysis of heat transfer through the finned tubes of ambient air vaporizers under the conditions of total frosting.
\end{abstract}

\section{Introduction}

Natural gas in its liquid state is commonly known as LNG and is the cleanest of the fossil fuels that competes with oil or coal. The use of LNG continues to grow worldwide in both stationary and mobile applications. Liquefied natural gas is stored at cryogenic temperature under pressure. Small and medium LNG storage tanks are designed as double-walled tanks insulated with vacuum and high performance cryogenic insulations [1]. Such tanks must include an internal support system, the design of which limits heat transfer to the tank [2]. For the direct use of natural gas, stored in the liquefied state, there is a need to obtain the gas phase by vaporization. It is achieved by supplying the appropriate amount of heat, most often using ambient air vaporizers. Ambient air vaporizers with longitudinal finned tubes are the most common. Such vaporizers have the form of a block with dimensions depending on the length of finned tubes, their number and spacing pitch. Aluminium alloys are used in the production of finned tubes due to their high thermal conductivity and the possibility to extrude fins of relatively large dimensions. During the operation of vaporizers, frost and ice is formed on the surface of lamellas of finned tubes containing low temperature liquefied gas as shown in Fig. 1. This is a typical phenomenon caused by condensation of moisture from the ambient air. A significant amount of ice is formed mainly on tubes containing the liquid phase under cryogenic temperature. To avoid the ice deposited on adjacent tubes from sticking together, the tubes containing the liquid phase are spaced at a greater distance than the tubes containing the gas phase. Ice melt during breaks in operation or when continuous cycles of operation are required, two or more vaporizers are used which are switched between each other at the station. The formation of frost has a disadvantageous effect on the vaporizer operation. Accumulated ice has the effect of increasing the mechanical load acting on the finned tubes, decreasing the space between them, and by reducing the heat flow, it affects the efficiency of the vaporizer.

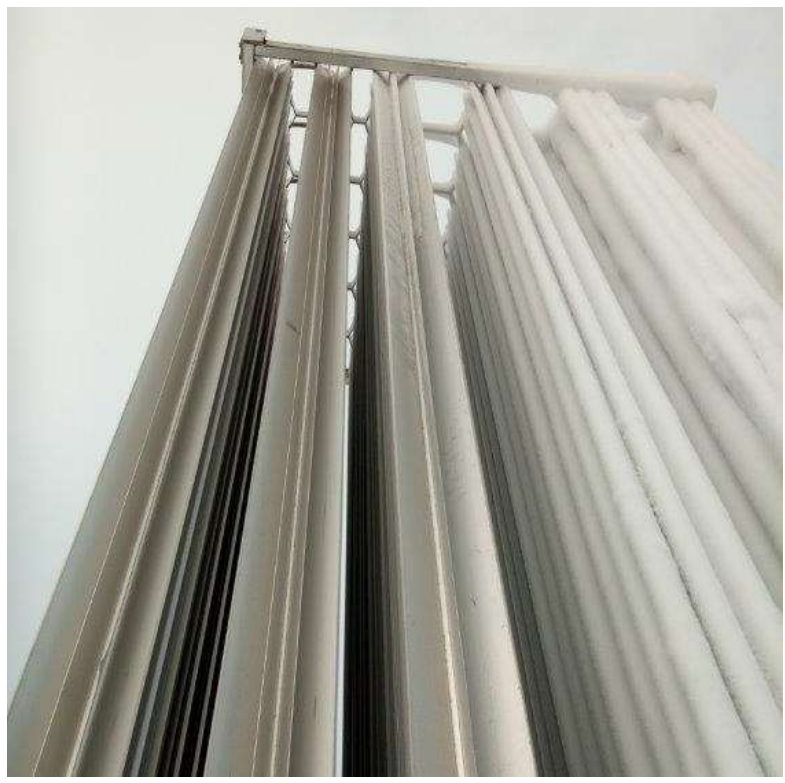

Fig. 1. Longitudinal finned tubes with accumulated ice.

Issues related to frost formation and the design and operation of vaporizers with longitudinal finned tubes have been addressed by several authors in previous publications. In the in paper [3], an analytical model of frost formation for the one-dimensional problem was

* Corresponding author: filip.lisowski@pk.edu.pl 
proposed. The relationship between air humidity and cold flat surface temperature as well as the relationship between air velocity and frost layer thickness were evaluated. In paper [4], results of numerical and experimental analysis on the relationship between frost layer thickness, temperature inside the tube, angle between fins and thickness of fins were presented. The determined relationships were used for optimal design of vaporizers. The authors of the paper [5] presented a coupled dynamic heat transfer model related to frost formation and boiling heat transfer of LNG in a longitudinally finned tube. It was found that the thermal resistance of the frost layer increases with operating time and is the main contributor to the temperature of the tube fins. The authors of paper [6] proposed a new boundary condition treatment at the outer boundary of finned tubs to simulate the laminar natural convection heat transfer around a horizontal finned tubes. It was found that for particular fins number existed an optimum fin height for which total heat transfer obtained its maximum. The paper [7] presented a CFD analysis of a one meter long finned tube of the ambient air vaporizer. Nitrogen was considered as a cryogenic liquid, and the ambient air was assumed to be dry. The presented results showed a proportional relation for the Rayleigh number and the Nusselt number in the specific range. In the paper [8], the authors presented a study of the heat transfer process on the outer surface of a vertical longitudinally finned tube during air flow under natural and forced convection conditions. The determination of local heat transfer coefficients was the objective of the analyses. CFD analysis was used to verify experimental. The author of the paper [9] presented the application of CFD analysis to predict the conditions of fog cloud formation and dispersion around a station incorporating six ambient air vaporizers. It was also shown that the phenomenon of frost accumulation on finned tubes affected the heat transfer coefficient and reduced the efficiency of the evaporators.

The purpose of study presented in this paper was the application of finite element thermal analysis to determine the heat transferred per unit length of longitudinal finned tubes and to compare its decrease due to frosting. A case for which the tubes were entirely covered with ice and the heat transfer from the environment by natural convection was considered.

\section{The object of study}

Two cross-sections of longitudinal finned tubes including four and eight fins around central pipe, as shown in Figs.1-2, were considered in the analysis. The outer diameter of both sections was $220 \mathrm{~mm}$, the inner diameter of the central tube was $20 \mathrm{~mm}$, the fin height was about $90 \mathrm{~mm}$, and the thickness of all walls was 2.5 $\mathrm{mm}$. During the operation of vaporizers, especially the tubes in the first row, become completely covered with frost and then ice. The ice layer completely covering the tube may have an irregular shape. For the current analysis, the outer shape of the ice deposit was assumed to be circular, , as shown in Figs.4-5.

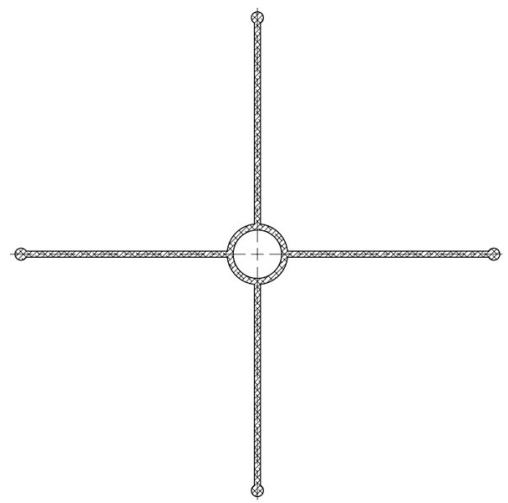

Fig. 2. Cross-section of the tube with 4 fins.

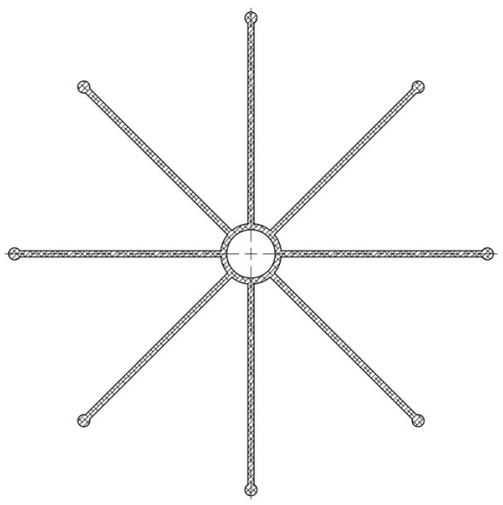

Fig. 3. Cross-section of the tube with 8 fins.

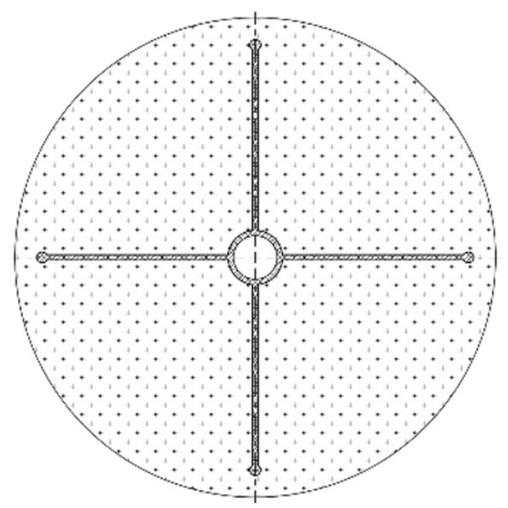

Fig. 4. Cross-section of the tube with 4 fins totally covered by ice.

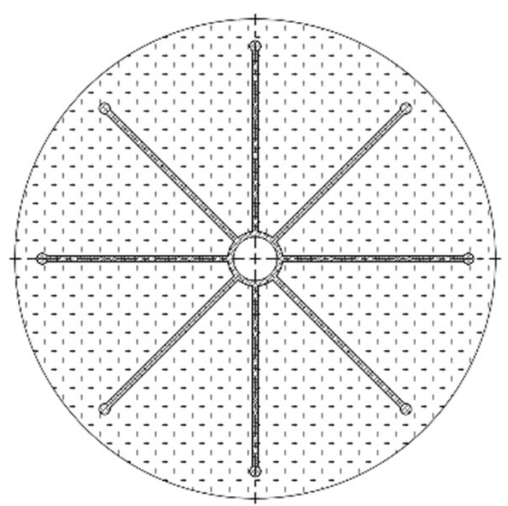

Fig. 5. Cross-section of the tube with 8 fins totally covered by ice. 


\section{Finite element thermal analysis}

\subsection{Finite element model}

Analysis referred to one meter length finned tubes of cross-sections including four and eight fins uniformly distributed around the perimeter. Steady-state thermal analysis was performed using Ansys software. The problem was considered as two dimensional. 8-node shell elements were accepted. The mesh accepted in the analysis for the example of tube with eight fins is shown in Figs. 6-7. Same finite element size was assumed for all calculation cases.

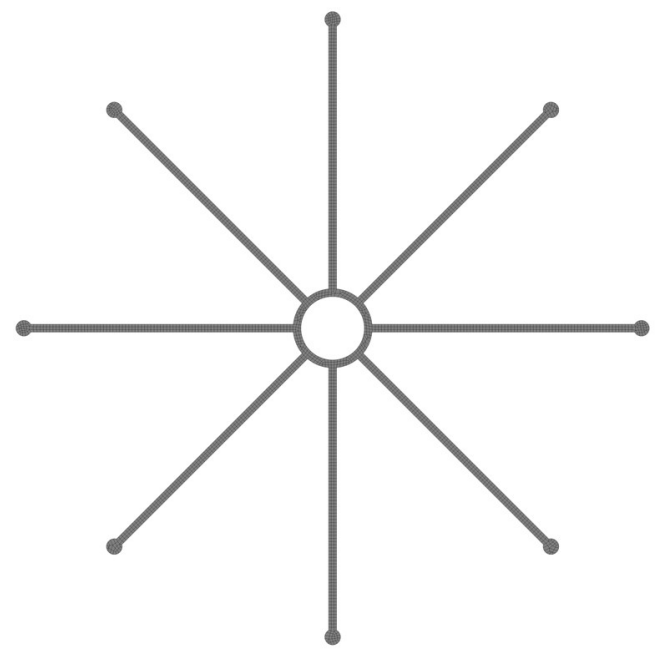

Fig. 6. Mesh of the tube with 8 fins without ice.

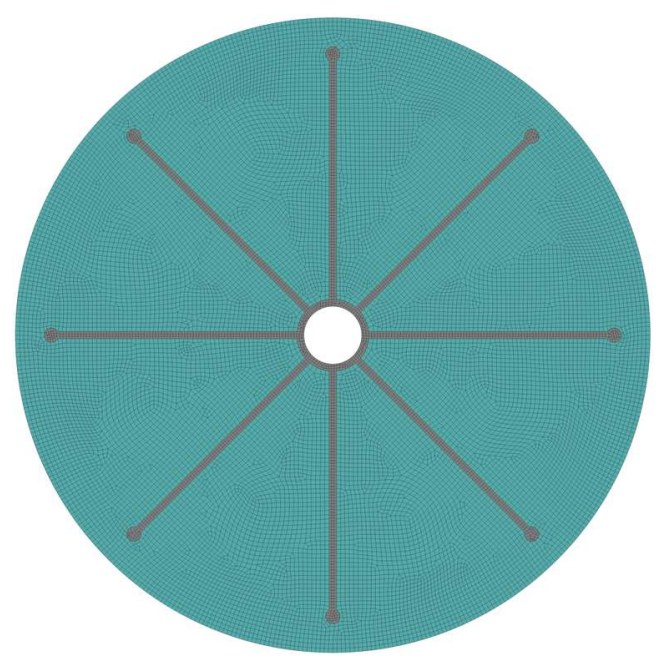

Fig. 7. Mesh of the tube with 8 fins entirely totally by ice.

\subsection{Thermal analysis assumptions}

- The material of finned tubes was aluminium with average thermal conductivity of $120 \mathrm{~W} /\left(\mathrm{m} \cdot{ }^{\circ} \mathrm{C}\right)$.

- The inner surface of the central pipe had a constant temperature of $-160^{\circ} \mathrm{C}$.
- Heat transfer on the outer surface of the finned tube or ice layer was by natural convection with a convection coefficient of $7 \mathrm{~W} /\left(\mathrm{m}^{2} \cdot{ }^{\circ} \mathrm{C}\right)$.

- Thermal conductivity od frost was accepted as a constant value of $0,2 \mathrm{~W} /\left(\mathrm{m} \cdot{ }^{\circ} \mathrm{C}\right)[10]$.

\subsection{Results}

The results of thermal analysis were presented in Figs. 7-8 as temperature distributions for the case of total frosting. In turn, heat at the tube outer surface related to one meter length of the finned tube was presented in Table 1.

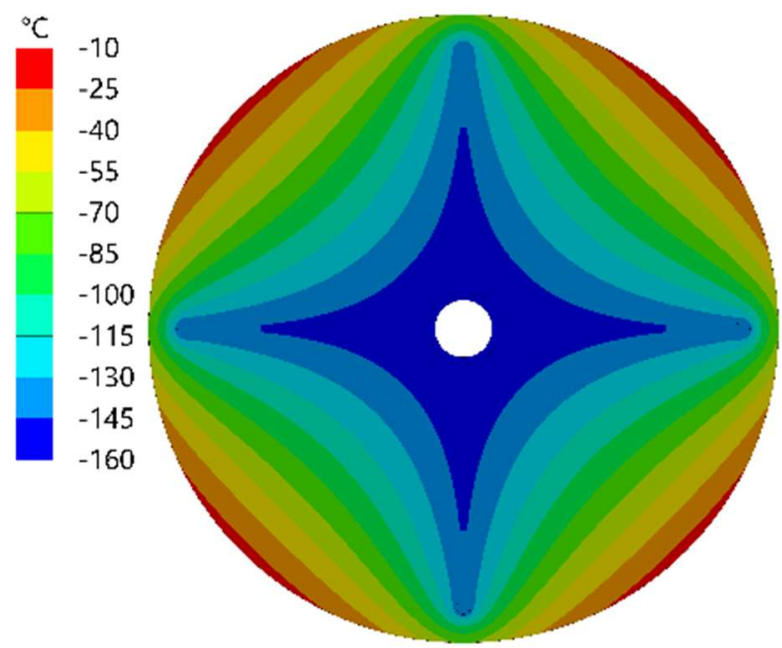

Fig. 8. Temperature distribution -4 fins with ice.

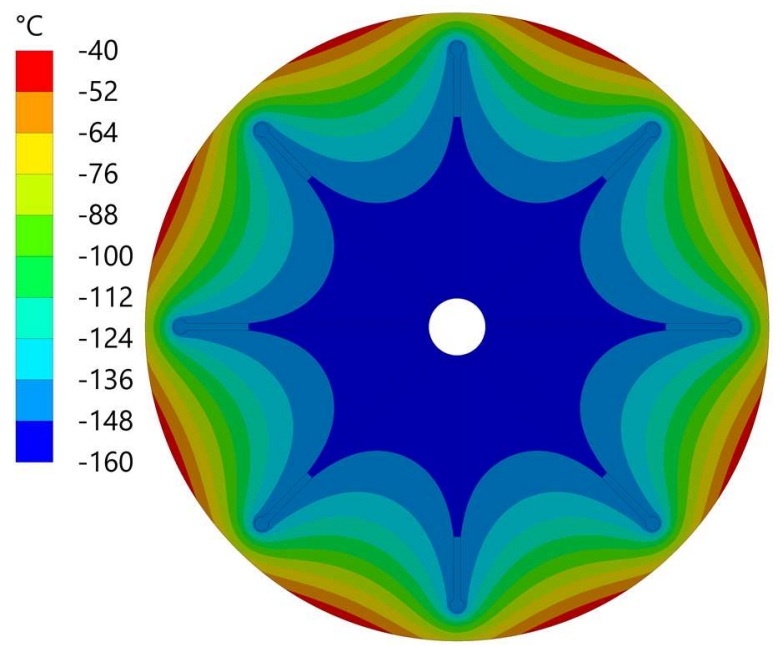

Fig. 9. Temperature distribution -8 fins with ice.

Table 1. Heat transferred per one meter of finned tube length.

\begin{tabular}{|c|c|c|c|}
\hline $\begin{array}{c}\text { Tube cross- } \\
\text { section }\end{array}$ & $\begin{array}{c}\text { Heat }[W] \\
\text { no frosting }\end{array}$ & $\begin{array}{c}\text { Heat }[W] \\
\text { total } \\
\text { frosting }\end{array}$ & $\begin{array}{c}\text { Heat } \\
\text { decrease }\end{array}$ \\
\hline 4 fins & 857 & 309 & $64 \%$ \\
\hline 8 fins & 1338 & 414 & $69 \%$ \\
\hline
\end{tabular}




\section{Conclusions}

From the results of the analysis, it can be observed that the heat transferred through the tube decreases significantly in the case of total frosting. The decrease in heat transfer was significant in both cases and reached about $64-69 \%$. It can also be observed that for tubes completely covered by frost, the heat transferred from the ambient air did not significantly depend on the number of fins. Therefore, such tubes do not require a large number of fins, as they have a minor effect on the amount of heat transferred.

\section{References}

1. E. Lisowski, F. Lisowski, Study on thermal insulation of liquefied natural gas cryogenic road tanker, Therm. Sci. 23, 4 (2019), S1381-S1391

2. F. Lisowski, E. Lisowski, Design of internal supports for double-walled liquefied natural gas road tanker, Heat Transfer Eng. (2021), 1-10

3. K.S. Lee, W.S. Kim and T.H. Lee, $A$ onedimensional model for frost formation on a cold flat surface, Int. J. Heat Mass Trans 40, 18 (1997), 4359-4365

4. H.M. Jeong, H.S. Chung, S.C. Lee, et al., Optimum design of vaporizer fin with liquefied natural gas by numerical analysis, J. Mech. Sci. Technol. 20, 4 (2006), 545-553

5. L. Shanshan, J. Wenlin, R. Lemei, et al., Dynamic heat transfer analysis of liquefied natural gas ambient air vaporizer under frost conditions, Appl. Therm. Eng. 110 (2017), 999-1006

6. J. M. Wu, W. Q. Tao, Numerical Computation of Laminar Natural Convection Heat Transfer around a Horizontal Compound Tube with External Longitudinal Fins, Heat Transfer Eng. 28, 2 (2007) 93-102

7. H.M. Jeong, Y.H. Lee, M.K. Ji, et al., Natural convection heat transfer estimation from a longitudinally finned vertical pipe using CFD, J. Mech. Sci. Technol. 23 (2009), 1517-1527

8. P. Kopeć, B. Niezgoda-Żelazko, Heat transfer on the outer Surface of vertical longitudinally finned tubes, IOP Conf. Series: Earth and Environmental Science 214, 012058 (2019)

9. F. Gavelli, Computational fluid dynamics simulation of fog clouds due to ambient air vaporizers, J. Loss Prev. Process Ind. 23 (2010), 773-780

10. C. Shuping, Shuting Y, Fusho X. Analysis of thermal conductivity of frost on cryogenic finnedtube vaporizer using fractal method, Energy and Power Engineering 5 (2013), 109-115 